\title{
Entre paredes e redes: o lugar da mulher nas famílias pobres
}

\section{Among walls and nets: women's place in poor families}

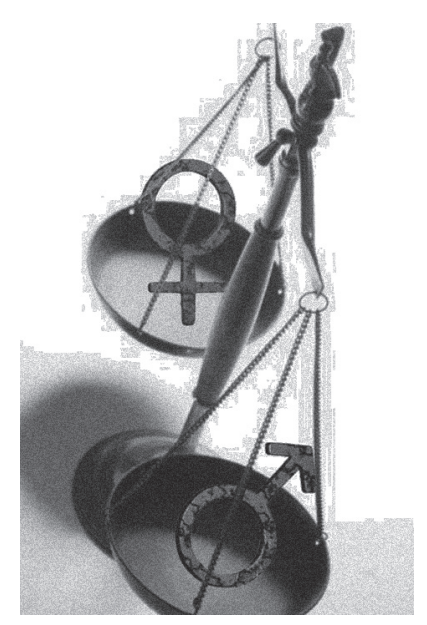

Verônica Gonçalves Azeredo*

Resumo: Em que medida a desigualdade de gênero pode incidir sobre a condição de pobreza e as formas de proteção das famílias? Essa é a questão norteadora deste texto. Trata-se de pensar qual o lugar da mulher nas famílias pobres. No espaço doméstico, essas mulheres, ao assumirem a identidade de mães, se tornam as principais responsáveis por prover e cuidar de sua família e, mesmo habitando espaços desiguais, criar alternativas constituindo redes de apoio e proteção para driblarem as inseguranças sociais.

Palavras-chaves: Pobreza. Desigualdade. Gênero. Famílias. Proteção social.

\begin{abstract}
To what extent may gender inequality fall over the situation of poverty and the ways of protecting the family? This is the main question of this text. It discusses women's place in poor families. In the domestic sphere, these women, taking over the identity of mothers, become primarily responsible for providing and caring for their families, and even when they live in uneven spaces, they create alternatives to have support and to protect from social insecurities.
\end{abstract}

Keywords: Poverty. Inequality. Gender. Family. Social protection

* Doutoranda em Política Social pela UFF/Niterói/RJ — Brasil; professora-adjunta do curso de Serviço Social pela UFF/Campos dos Goytacases — RJ. E-mail: vgazeredo@gmail.com. 


\section{Introdução}

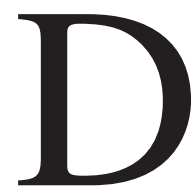

e abordagem conceitual, o texto tem como proposta resumir e apontar o lugar da mulher na família e as relações de proteção social travadas nos espaços onde a pobreza é condição. Enquanto figura central da vida doméstica, a mulher vem merecendo destaque na esfera pública como pessoa de referência para o recebimento de benefícios sociais devido ao fato de aplicar melhor dos recursos no âmbito familiar. No entanto, apesar do reconhecimento quanto aos cuidados e proteção da família, as políticas não têm se voltado para a perspectiva de gênero e desse modo, as desigualdades e discriminações continuam incidindo sob formas injustas de oportunidades. No contexto da pobreza, e mais especificamente da vulnerabilidade acentuada, as mulheres, para driblarem as inseguranças sociais, acabam tecendo redes de apoio, em geral com outras mulheres, e por meio dessas relações sociais com os mais próximos ocupam o lugar onde o Estado e o mercado não chegam, prestando relevantes serviços no enfrentamento das condições de pobreza.

\section{Habitando espaços desiguais: condição da mulher nas familias pobres}

Se iniciarmos tomando a desigualdade do ponto de vista da "natureza" humana, podemos afirmar que os seres humanos são diferentes entre si. É nesse sentido que Arent chama atenção para "a pluralidade da condição humana pelo fato de sermos todos os mesmos, isto é, humanos, sem que ninguém seja exatamente igual a qualquer pessoa que tenha existido, exista ou venha existir" (1991, p. 36).

Sendo assim, a igualdade é construída socialmente, e esta por sua vez difere em cada sociedade por meio dos valores atribuídos às relações sociais e dos critérios de distribuição dos recursos que estruturam a vida social.

Portanto, do ponto de vista econômico-social, a desigualdade não pode ser pensada enquanto um conceito em si, só tendo sentido se estabelecida às relações históricas e inter-relacionadas entre os papéis sociais e as estratificações que colocam os sujeitos em posições favoráveis ou desfavoráveis em termos de lugar social. 
Na definição desses lugares materiais e simbólicos, a desigualdade interage com diversos elementos correlacionados. Trata-se de processos dependentes, como é o caso da relação entre desigualdade e pobreza. É nesse sentido que Prates ressalta que um "aumento da desigualdade, na maioria das vezes, implica aumento da pobreza. Mas a diminuição da desigualdade não garante uma melhora nos indicadores de pobreza, podendo ocorrer uma redistribuição de renda entre setores mais ricos" (1990, p. 61).

Isso confere à desigualdade um caráter relativo, na medida em que seu sentido é estabelecido na relação com determinantes econômicos, políticos e sociais, entre outros. No caso brasileiro, esses determinantes são conhecidos e reconhecidos pelo modo como os grupos sociais têm acesso, não acesso, ou acesso precarizado a bens e recursos. Assim sendo, o Brasil é identificado por organismos internacionais como um dos países de maior desigualdade social. Segundo Urani, "o Brasil não é um país pobre, mas com muitos pobres” (2009, p. 1).

É nessa mesma linha que Telles afirma que a pobreza se transformou em paisagem, um desenho de uma gente desumanizada e abandonada, sem pai ou mãe, "um efeito indesejado de uma história sem autores e responsabilidades" (1994, p. 6). Para a referida autora, "o problema da igualdade parece se esgotar no acesso aos mínimos de sobrevivência” (1999, p. 9). Portanto, fora do contrato social, os que encarnam a pobreza absoluta vivem sob os imperativos da sobrevivência. Por pobreza absoluta entende-se o não acesso a mínimos necessários a sobrevivência física, enquanto na pobreza relativa isso é garantido, porém em patamares insuficientes, inscrevendo os sujeitos, em condições de vulnerabilidade e riscos sociais.

Há uma diversidade de indicadores que apresentam a realidade das famílias em termos de padrões de vida e apropriação de renda. Barros, Henriques e Mendonça em suas análises sobre a desigualdade e pobreza no Brasil, afirmam que

a abordagem conceitual da pobreza absoluta requer a construção de uma medida invariante no tempo das condições de vida dos indivíduos em sociedade. A noção de linha da pobreza equivale a essa medida. Há pobreza apenas na medida em que existem famílias vivendo com renda per capita inferior ao nível mínimo necessário para que possam satisfazer as necessidades básicas. (Barros, Henrique e Mendonça, 2000, p. 124) 
Que nível mínimo seria esse? Quem está “autorizado” a instituí-lo? Quais são os critérios utilizados? É coerente homogeneizar a satisfação das necessidades básicas? Qual a participação e percepção das famílias pobres sobre esses critérios? Essas e tantas outras questões povoam as reflexões daqueles que se debruçam sobre o tema.

Na visão de Reis (2000, p. 138), "a crença de grande parte dos economistas de que as representações numéricas refletem uma 'realidade' inconteste não parece ter lugar para as 'descrições' dos cientistas sociais". A perspectiva da referida autora é a de que embora imprescindíveis, os números não explicam as estratificações e a mobilidade social, fenômenos que requerem um olhar sociológico.

Embora o diálogo se estabeleça entre as perspectivas de produção intelectual quanti-qualitativas, a pobreza aí está materializada como produto da desigualdade, generalizada histórica e geograficamente.

Hoje, várias são as abordagens em torno da pobreza. O discurso pautado na ótica da sobrevivência física vem cedendo espaço para concepções menos restritivas a partir da introdução de variáveis mais amplas, como é o caso do conceito desenvolvido por Amartya Sem, que parte da premissa de que ser pobre não implica somente privação material. As privações sofridas determinarão a posição dos sujeitos nas outras esferas (1999, p. 73).

Desse modo, há que se perceber o caráter multidimensional da pobreza. Além de privações materiais, os pobres estão expostos a maiores vulnerabilidades e riscos sociais. Associa-se a essa ideia a falta de oportunidades de expressão e, consequentemente, de escuta sobre o que eles têm a dizer sobre sua condição. Nesse sentido, tomo emprestado de Crespo e Gurovitz uma definição de pobreza pelos pobres:

Pobreza é fome, é falta de abrigo. Pobreza é estar doente e não poder ir ao médico. Pobreza é não poder ir à escola e não saber ler. Pobreza é não ter emprego, é temer o futuro, é viver um dia de cada vez. Pobreza é perder o seu filho para doença trazida pela água não tratada. Pobreza é falta de poder, falta de representação e liberdade. (2002, p. 11)

Assim como a pobreza deve ser conjugada no plural, família é outro conceito que suscita variadas concepções. Aqui nos interessa pensar as famí- 
lias regidas sob o signo da pobreza. Imersas em desigualdades históricas quanto aos modos de ser e de viver e representadas por vezes como desestruturadas, tais famílias vivenciam a realidade do desemprego ou inserções precárias cujas consequências são os baixos rendimentos, a falta de oportunidades educacionais, acesso limitado e baixa qualidade dos serviços de saúde e infraestrutura habitacional, segregação sócio-espacial. Tudo isso conforma um conjunto de desvantagens sociais alimentadas pelo caráter limitado de seu patrimônio cultural.

Desse modo, as identidades das famílias pobres vão se desenhando através de visíveis fronteiras territoriais. Por território entende-se o que Milton Santos (2007, p. 14) refere-se como "território usado": "O território usado é o chão mais a identidade. A identidade é o sentimento de pertencer àquilo que nos pertence. O território é o fundamento do trabalho: o lugar da residência, das trocas materiais e espirituais e do exercício da vida". É o espaço onde a família se define. Importa compreender como o sujeito feminino é construído dentro de estruturas de dominação socioespaciais, o modo como é representado, o lugar na família, bem como suas formas de responsabilização.

É necessário lembrar que o padrão dominante de família instituído nas sociedades industrializadas conferiu a mulher o espaço dos cuidados domésticos e afetivos. É nesse sentido que Vaitsman afirma que "a sociedade industrial moderna constituiu-se, entre outras coisas, pela separação do público e do privado e pela doutrina das esferas separadas por naturezas sexuais desiguais, expressas na ideologia, nas políticas e na legislação" (1994, p. 60).

Apesar dos avanços obtidos em termos de igualdade jurídica para mulheres e homens, no plano social e político verifica-se que ainda prevalecem as desigualdades de oportunidade.

A realidade de conciliação entre a vida familiar e trabalho, dos precários rendimentos, de pais ausentes, de formas desiguais de responsabilidade familiar, entre outras causas sociais, tem possibilitado alterações na dinâmica das famílias. Diante dessas questões Szmanski destaca que "o mundo familiar mostra-se numa vibrante variedade de formas de organização, com crenças, valores e práticas desenvolvidas na busca de soluções para as vicissitudes que a vida vai trazendo" (1995, p. 27).

Isso nos remete ao fato de que a família deve ser pensada no plural. Vários são os modos de estabelecer suas relações, sintonizados com as mudanças sociais 
em curso. No entanto, se a família muda, o que se conserva é o seu lugar social. Tida como mediadora da relação indivíduo-sociedade assume ainda o papel do encontro de gerações.

Esse "encontro" é também desencontro. Se tomarmos a família como espaço de ambiguidades e contradições perceberemos que ela não é só o ninho, mas também o nó. Lócus de pertencimento e de visíveis fronteiras aí está, configurada e (re) configurada. O fato é que, movidos por questões afetivas e socioeconômicas, os sujeitos se aproximam e desenham um modo de viver e atender suas necessidades. Nesse sentido, a família é uma forma de organização social bem sucedida. Do ponto de vista da convivência, Arendt afirma que "nenhuma vida humana, nem mesmo a de um eremita, é possível sem um mundo que, direta ou indiretamente, testemunhe a presença de outros seres humanos" (1991, p. 31).

É no contexto dessa vida em comum e desses "modos de ser", que nos interessa pensar como as mulheres das famílias pobres vivem e constroem suas identidades, assentadas na perspectiva de gênero. ${ }^{8}$

Os espaços nos quais habitam e transitam revelam visíveis formas de discriminações. Portanto, apreender as práticas dessas mulheres e o modo como se representam e são representadas se torna fundamental para compreender a natureza dos processos discriminatórios e a elaboração de outros marcadores identitários.

No espaço da casa e entre paredes, as mulheres ainda ocupam espaços desiguais. Se nas últimas décadas conquistaram o espaço público, este fez aumentar sua responsabilidade, ao ter que conciliá-lo com o espaço privado.

Se tomarmos o fator tempo, compreenderemos o quanto este incide sobre a vida dessas mulheres, ao vê-lo consumido no exercício de suas atividades. Goldani mostra que "a dupla jornada de trabalho é muito mais comum entre as mulheres e que entre os domicílios $20 \%$ mais pobres são de mulheres que trabalhavam dezessete horas a mais que os homens, diferenças essas que diminuem para onze horas quando as mulheres pertencem aos domicílios $20 \%$ mais ricos" (1997, p. 6).

8. Gênero como categoria transversal, que se encontra na interface das inúmeras afiliações sociais de homens e mulheres. Não possui um contexto organizacional específico, e como tal é parte integrante da construção social quotidiana nas diversas práticas que os indivíduos levam a efeito (Goldani, 1999, p. 6). 
Os processos que possibilitaram a saída das mulheres para o trabalho não motivaram a revisão das funções do cuidado familiar no que diz respeito à divisão das tarefas domésticas.

Esse é sem dúvida um dos eixos que estruturam a desigualdade de gênero. Pensá-lo nos remete a importância de articulá-lo com a noção de autonomia pessoal e econômica e como estes aspectos incidem sobre a vida das mulheres pobres.

Em pesquisa realizada por Lavinas e Nicoll "o desemprego mostra-se fortemente feminizado" (2006, p. 53). Isso tem relação direta com a autonomia, na medida em que a redução dos encargos domésticos tende a aumentar as possibilidades de entrada no mercado de trabalho.

Os referidos pesquisadores apontam para algumas variáveis que podem aumentar os ganhos das mulheres ocupadas, ainda que na informalidade.

Ter máquina de lavar é a variável que mais contribui para elevar a renda das mulheres pobres ocupadas ( $\mathrm{R} \$ 54,15$ ), aumentando-a em $42 \%$. Outro fator importante é a presença de uma mulher inativa no domicílio ( $\mathrm{R} \$ 22,45)$, sem dúvida por assumir certas responsabilidades familiares. Se essa figura for aposentada ou pensionista, talvez ela ainda esteja contribuindo para assegurar uma renda mínima permanente nesses lares mais desfavorecidos e, assim, facilitar a inserção dessas mulheres no mercado de trabalho, inclusive ampliando seu leque, restrito, de oportunidades. (Lavinas e Nicoll, 2006, p. 59)

É nesse sentido que a autonomia pessoal pode incidir sobre a autonomia econômica. E esse aspecto é extremamente relevante, visto que as mulheres tendem a serem mais vulneráveis as condições de pobreza, por terem restritas as oportunidades de ampliação de seus rendimentos e de interações que lhes confira o aumento de seu patrimônio cultural.

O que as pesquisas ${ }^{9}$ têm mostrado é que não há feminização da pobreza no Brasil. As famílias chefiadas por mulher sem cônjuge "correspondem a um quinto dos pobres" (Costa et al., 2005, p. 36). No entanto, há que se considerar que as famílias cuja mulher é a única responsável pelos filhos têm necessidades distintas daquelas chefiadas por casais.

9. Sobre feminização da pobreza, ver: Novelino (2003), Lavinas (2006), Soares (2004) e Carloto (2004). 
O fato é que em geral, ao tomar como referência a renda per capita, os dados quantitativos encobrem evidências qualitativas, que por sua vez não capturam variáveis importantes do ponto de vista da multidimensionalidade da pobreza e do gênero. Nesse sentido, Costa considera que deve se tomar como referência analítica as características individuais, como "o uso do tempo, a inserção no mundo do trabalho, o acesso a títulos de propriedade, que evidenciam a heterogeneidade da pobreza e indiquem que a posição dos indivíduos na família, sua idade, sexo, raça, determinam formas diferenciadas de enfrentar o fenômeno" (Costa et al., 2005, p. 37).

O fato é que a constituição das famílias monoparentais está relacionada mais às mulheres do que aos homens. Segundo Novelino (2003, p. 2), há uma tendência para o aumento da pobreza entre as mulheres, associada ao aumento das taxas de domicílios por elas chefiados. O que ocorre é que independente do gênero, assumir sozinho a responsabilidade pela família significa não poder compartilhar responsabilidades e ônus, o que, por sua vez, é um indicador de maior vulnerabilidade.

As condições de vulnerabilidade se acentuam não só pelo lugar da mulher na família, mas também pela família de determinado lugar. Importa pensar a dimensão geográfica da pobreza e o quanto isso recai sobre as famílias e mais especificamente sobre as mulheres.

A geografia da miséria urbana conforma um mapa que segrega e empurra para pessoas e oportunidades a margem. Ao se referir aos problemas da periferia, Bourdieu (1998, p. 27) destaca que: "trata-se de uma inserção precária marcada por lugares de ausência, ausência do Estado, da polícia, da escola etc". Isso impacta diretamente a vida das mulheres que habitam a periferia, pois "na falta de serviços públicos, são elas que o fazem" (Soares, 2004, p. 121).

O local de moradia é outro indicador importante para se pensar a autonomia das mulheres. Ao habitarem lugares com difícil acesso a recursos materiais e simbólicos, veem suas condições de pobreza ser produzidas e reproduzidas, num círculo perverso que conforma a falta de melhores oportunidades, confinando-as num lugar muito distante dos padrões minimamente aceitáveis. $\mathrm{Na}$ visão de Paugam, tal condição materializa-se "sob a forma de estigma que desenha com traços negativos o cotidiano e a identidade sociocultural dos moradores das áreas periféricas, cuja segregação é percebida através de visíveis fronteiras territoriais" (2003, p. 45). 
Tais fronteiras reforçam a distância entre a vida pública e a privada e alimentam eixos que constroem a desigualdade no cotidiano das mulheres pobres pela falta de autonomia do corpo e da sexualidade e que também acabam por desaguar na falta de autonomia pessoal e econômica. Um dos marcadores mais importantes da identidade feminina é, sem dúvida, a maternidade. A condição de mulher, sempre associada ao papel de mãe, cuja responsabilidade no cuidado com os filhos parece uma imposição da ordem da natureza, limita as oportunidades de construção de outros marcadores identitários necessários à ordem civilizatória.

Longe dos benefícios e vantagens que seu lugar social não pode proporcionar, essas mulheres acabam tecendo redes sociais e alternativas peculiares a partir do vivido. Apropriam-se do seu lugar e da sua condição, dos saberes e fazeres compartilhados, em busca de proteção.

\section{Redes de proteção: refúgio das inseguranças sociais}

Como controlar os riscos da existência social quando faltar trabalho ou não se puder mais trabalhar? "Controlar o futuro, já que o presente era instável": foi sobre essa noção que se consolidou o sistema de seguridade social, como uma das grandes conquistas dos trabalhadores. Por essa razão, Castel se refere às consequências dos processos de "mundialização da economia", destaca que pior do que o fenômeno do desemprego (hoje em escala global) é a perda das proteções sociais, tão duramente conquistadas. $\mathrm{O}$ desejo de sentir-se protegido é condição íntima do sujeito, destaca (Castel, 1998, p. 171).

Refere-se ao contexto das sociedades europeias que viveram a experiência do pleno emprego e por isso tornaram-se símbolos da cidadania contemporânea. No caso brasileiro, o emprego não alcançou o status de valorização humana pelo trabalho, não foi possível "filiar" homens e mulheres conferindo-lhes a proteção a que deveriam ter direito. O trabalho no Brasil consolidou-se sob o signo da informalidade, da precarização e da desproteção. Desse modo, o acesso a condição de empregabilidade desenhou-se como privilégio, e não como condição. Nesse sentido, sujeitas a formas de assalariamento precário e vinculadas a um sistema protecionista que conforma a assistência como direito, porém se assenta nos "mínimos sociais", as famílias pobres brasileiras tornaram-se 
verdadeiras equilibristas na fronteira, público/privado, driblando toda ordem de insegurança social.

Na visão de Paugam, essa precariedade da vida profissional tende a ser compensada pela assistência. Toma de Simmel a noção de que o sujeito é qualificado como pobre "a partir do momento em que são assistidos ou quando sua situação lhes dá direito à assistência, mesmo se ela não tenha sido concedida, que eles passam a fazer parte de um grupo caracterizado pela pobreza" (Simmel, apud Paugam, 1999, p. 43).

Isso estabelecido nos leva a questionar: a que se refere o objeto da proteção social? Se partirmos do pressuposto de que "proteção social é uma ação contra os riscos inerentes à vida humana e (ou) a assistência às necessidades geradas em diferentes momentos históricos e relacionadas com múltiplas situações de dependência" (Viana e Levcovitz, 2005, p. 17), chegaremos à conclusão de que a dependência gera insegurança e vice-versa. Isso nos aponta para o fato de o objeto da proteção social se estabelecer na relação segurança e insegurança (Idem, p. 15).

É nesse sentido que proteção social e política social vinculam-se à necessidade de segurança individual e familiar. Pensar proteção é associar a dimensão do cuidado com o "outro". Mas quem cuida do "outro"? Aquele que desenvolve o senso de solidariedade em direção a uma causa, grupo ou indivíduo dentro de fronteiras de uma ambivalência mais próxima à nossa existência (física e mental) cotidiana. Essa é a noção de Rorty sobre o modo como construímos o nosso senso de pertencimento e criamos a habilidade de perceber o "outro" como merecedor de nossa solidariedade. O referido autor, não crê que a solidariedade seja um traço da personalidade humana. Esta só é possível num plano mais local, quando trazemos o "eles" para o "nós" (Rorty, apud Góis, 2002).

É a partir de referências próximas ao nosso cotidiano que as redes de solidariedade são tecidas no cruzamento indissociável das esferas públicas e privadas. Nesse assunto, é importante também a contribuição de Castel sobre proteção próxima e sociabilidade primária enquanto "formas de pertença à família, vizinhança, grupo de trabalho, com suas redes de interdependências, sem mediação das instituições específicas; e a proteção secundária, definida como o lugar das instituições criadas para aqueles que se desatrelaram das redes de sociabilidade primária" (Castel, 1998b, p. 59). 
Se tomarmos como referência as formas de solidariedade estabelecidas entre as mulheres pobres, verificaremos que estas sempre contaram com apoio de outras mulheres pobres como elas no cuidado com seus filhos, seja para o desempenho das tarefas domésticas ou fora desse ambiente. Segundo Costa, isso ocorre independentemente de haver ou não creches (Costa, 2002, p. 312).

O fato é que a forma de proteção secundária nem sempre está disponível e, nesse sentido, as práticas de proteção primária, enquanto responsabilidade das mulheres, por vezes se materializam em dinâmicas familiares alternativas como a prática de "circulação de crianças". ${ }^{10}$ Segundo Fonseca, trata-se de uma prática onde "cuidar das crianças não se limita à mãe, nem ao casal. Mobiliza uma rede de adultos que se estende para além do grupo de parentesco" (Fonseca, 2002, p. 57).

Isso permite às mães, sobretudo, os chefes de família, obter ganhos provenientes do trabalho para além do espaço doméstico. Para Bilac, a naturalização da relação mulher-cuidado é um dos indicadores que fazem com que elas sejam responsáveis pelas redes de parentesco e de vizinhança, ao passo que os homens estando mais distantes dessas redes, desenvolvem laços em estruturas de oportunidades mais amplas como as redes de trabalho e de lazer, sobretudo nos espaços dos bares (Bilac, 2006, p. 62).

Ao assumir a centralidade com o cuidado e proteção de seus familiares, a mulher tem também importância garantida na transmissão de oportunidades e perspectivas de vida dos mesmos.

Tal condição tem sido apropriada pelo Estado brasileiro, que, por sua vez, tem centrado os programas sociais na figura das mulheres para o recebimento dos benefícios. Sobre esse assunto, Carloto ressalta que "é necessário distinguir entre o que são programas que têm por alvo preferencial as mulheres e o que são programas com perspectiva de enfrentamento das desigualdades de gênero" (2004, p. 152).

O que poderia de fato gerar impacto na perspectiva de gênero e no enfrentamento das condições de pobreza, sobretudo nas famílias cuja responsabilidade econômica não é compartilhada, é o acesso a equipamentos sociais de qualidade, como creches, escola em tempo integral, serviço de saúde, entre outros

10. Sobre esse assunto consultar Fonseca (2002). 
que poderiam aliviar a carga de trabalhos domésticos e gerar melhores oportunidades de vida, emprego e rendimentos.

Apesar de as políticas públicas e sociais terem um lugar específico no que se refere às formas de enfrentamento da pobreza, acredita-se que sua contribuição poderia ser maior na redução de seu impacto caso houvesse, de fato, uma articulação entre diversos setores sociais como educação, emprego e renda, saúde, habitação, saneamento e urbanização. Deve-se se considerar a importância da formulação e da implementação de políticas intersetoriais, capazes de articular esses setores com a noção de que a pobreza é um problema coletivo (Bronzo e Veiga, 2007, p. 11).

Essa é, sem dúvida, uma questão polêmica, de modo que o conjunto da sociedade brasileira não tem demonstrado solidariedade com a pobreza e com os pobres. Até mesmo os profissionais que atuam na linha de frente das políticas e programas sociais carecem de recursos objetivos e subjetivos capazes de conciliar as demandas com a qualidade dos serviços prestados.

É nesse contexto de pobreza e vulnerabilidade que as famílias (centradas nas mulheres) buscam formas alternativas de proteção associadas aos "mínimos" das políticas governamentais, como refúgio das inseguranças sociais.

\section{Considerações finais}

Pensar desigualdade de gênero e associá-la ao fenômeno da pobreza implica questionamento de um contrato sexual truncado que, por sua vez, estabelece oportunidades desequilibradas e injustas, conferindo à mulher responsabilidades cada vez maiores, para cuidar e prover sua família.

O caráter multidimensional da pobreza e a pluralidade dos modos de ser e viver das famílias afetam diretamente a mulher, enquanto figura central da esfera doméstica.

Desse modo, a conciliação entre os afazeres domésticos e o trabalho fora do lar, impõe um duplo esforço na administração do tempo. Nesse sentido, a autonomia pessoal proporcionada pela "máquina de lavar" e pelo acesso a equipamentos sociais como creches, escolas e atendimento à saúde reprodutiva, pode influir na autonomia econômica das mulheres. 
Quando essas mulheres são as únicas responsáveis pelo provimento de sua família, a condição de vulnerabilidade se acentua, aumentando os riscos sociais. Em busca de apoio, tendem a tecer redes de solidariedade em geral com outras mulheres, sejam parentes ou vizinhas. E no contexto dessas relações demonstram o poder de enfrentamento diante das privações vivenciadas.

Trata-se de privações materiais e simbólicas acumuladas ao longo da vida e reproduzidas sob as formas de desigualdades e discriminações, inclusive por parte das políticas públicas, que mesmo tomando como alvo preferencial as mulheres, não tem se voltado para a perspectiva de gênero.

Artigo recebido em mar./2010 aprovado em jun./2010

\section{Referências bibliográficas}

ARENT, H. Condição humana. Rio de Janeiro: Forense Universitária, 1991.

BARROS, R. P. de; HENRIQUES, R.; MENDONÇA, R. Desigualdade e pobreza no Brasil: retrato de uma estabilidade inaceitável. Revista Brasileira de Ciências Sociais, v. 15, n. 42 , fev. 2000 .

BILAC, E. D. Gênero, vulnerabilidade das famílias e capital social: algumas reflexões. In: CUNHA, J. M. P. (Org.). Novas metrópolis paulistas: população, vulnerabilidade e segregação. Campinas: Nepo/Unicamp, 2006. p. 51-65.

BOURDIEU, P. A miséria do mundo. Petrópolis: Vozes, 1998.

BRONZO, C.; VEIGA, L. Intersetorialidade e políticas de superação da pobreza. Serviço Social \& Sociedade, São Paulo, ano 28, n. 92, nov. 2007.

CARDOSO, R. Movimentos sociais urbanos; balanço crítico. In: SORJ, B.; ALMEIDA, M. H. (Eds.). Sociedade e política no Brasil pós-64. São Paulo: Brasiliense, 1984. p. 215-239.

CARLOTO, C. M. Ruptura ou esforço da dominação: gênero em perspectiva. In: GODINHO, T.; SILVEIRA, M. L. (Orgs.). Políticas públicas e igualdade de gênero. São Paulo, 2004. p. 149-156. (Caderno da Coordenadoria Especial da Mulher, n. 8.)

CASTEL, R. Desigualdade e questão social. São Paulo: Educ; Petrópolis: Vozes, 1998. 
CASTEL, R. As metamorfoses da questão social: uma crônica do salário. Petrópolis: Vozes, 1998.

COSTA J. S. et al. A face feminina da pobreza: sobre-representação e feminização da pobreza no Brasil. Texto para Discussão, n. 1.137. Brasília, nov. 2005.

COSTA, S. G. Proteção Social, maternidade transferida e lutas pela saúde reprodutiva. Revista Estudos Feministas, Florianópolis, v. 10, n. 2, p. 301-324, 2002.

CRESPO, A. P. A.; GUROVITZ, E. A pobreza como fenômeno multidimensional. RAE-eletrônica, v. 1, n. 2, p. 1-11, jul.-dez. 2002.

FONSECA, C. Mãe é uma só? Reflexões em torno de alguns casos brasileiros. Revista Psicologia USP, São Paulo, n. 2, v. 13, p. 49-68, 2002.

GÓIS, J. B. H. A solidariedade como um projeto: o aporte teórico de Richard Rorty. Em Pauta, Rio de Janeiro, n. 17, 2002.

GOLDANI, Ana Maria. Famílias e gêneros: uma proposta para avaliar (des)igualdades. São Paulo, p. 1-20, 1997. Disponível em: <www.abep.nepo.unicamp>. Acesso em: 13 jul. 2009.

O regime demográfico brasileiro nos anos 90: desigualdades, oportunidades e restrições demográficas. In: GALVÃO, L.; DIAZ, J. (Org.). Saúde sexual e reprodutiva no Brasil: dilemas e desafios. São Paulo: Hucitec, 1999. p.25-69.

LAVINAS, L; NICOLL, M. Pobreza, transferência de renda e desigualdades de gênero: conexões diversas. Parcerias Estratégicas, Brasília, v. 22, p. 39-75, 2006.

NOVELINO, M. S. F. Os estudos sobre feminização da pobreza: origens e tendências atuais. In: SEMINÁRIO INTERNACIONAL DE EDUCAÇÃO INTERCULTURAL, GÊNERO E MOVIMENTOS SOCIAIS, 2, Florianópolis, Anais..., p. 1-11, 2003.

PAUGAM, S. Fragilização e ruptura dos vínculos sociais: uma dimensão essencial do processo de desqualificação social. Serviço Social \& Sociedade, São Paulo, v. 20, n. 60, jun. 1999.

A desqualificação social: ensaio sobre a nova pobreza. São Paulo: Educ/Cortez, 2003.

PRATES, C. A. Mensuração da pobreza: o dedo na ferida. São Paulo em Perspectiva, São Paulo, v. 4, n. 2, p. 59-63, 1990.

REIS, E. P. Percepções da elite sobre a pobreza e desigualdade. Revista Brasileira de Ciências Sociais, São Paulo, v. 15, n. 42, fev. 2000. 
SANTOS, M. O dinheiro e o território. In: . et al. Território, territórios: ensaios sobre o ordenamento territorial. 3. ed. Rio de Janeiro: Lamparina, 2007. p. 13-21.

SEN, A. K. Sobre ética e economia. São Paulo: Companhia das Letras, 1999.

SOARES, V. Políticas Públicas para igualdade: papel do Estado e Diretrizes. In: GODINHO, T.; SILVEIRA, M. L. (Orgs.). São Paulo, 2004. p. 113-126. (Cadernos da Coordenadoria Especial da Mulher, n. 8.)

SZMANSKI, H. C. B. (Org.). A família contemporânea em debate. São Paulo: Cortez, 1995.

TELLES, V. Pobreza e Cidadania: duas categorias antinômicas. Mínimos de cidadania: ações afirmativas de enfrentamento à exclusão. Cadernos do Núcleo Social Seguridade e Assistência Social, São Paulo, 1994.

. Direitos sociais: afinal do que se trata. Belo Horizonte: Ed. da UFMG, 1999.

URANI, A. Crescer não basta. Revista Sebrae, Rio de Janeiro, n. 12, 2009.

VAITSMAN, J. Flexíveis e plurais: identidade, casamento e família em circunstância pós-moderna. Rio de Janeiro: Rocco, 1994.

VIANA, A; LEVCOVITZ, E. Proteção social: introduzindo o debate. In: VIANA. A; ELIAS, P. IBANEZ. N. (Org.). Proteção social: dilemas e desafios. São Paulo: Hucitec, 2005. p. 15-57. 